\title{
"Inglês sem distância": um relato de experiência de oferta de um minicurso de Inglês a distância para alunos do interior de Pernambuco
}

\author{
Paula Basto Levay ${ }^{1}$, Fabiana de Barros Monteiro Soares ${ }^{2}$, Marizete Silva Santos ${ }^{1}$ \\ ${ }^{1}$ Universidade Federal Rural de Pernambuco- Rua Manoel de Medeiros s/n. Dois \\ Irmãos- Recife/PE- Brasil
}

${ }^{2}$ Universidade de Pernambuco- Rua Benfica 455. Madalena- Recife/PE- Brasil

paula_levay@hotmail.com, fabianabms@hotmail.com,
marizeteufrpe2@gmail.com

\begin{abstract}
This article presents the results of a mini-course of English, firsttime delivered for distant learning Pedagogy students of UFRPE, who lived in the countryside of the state of Pernambuco. The objective of the work was to analyze the students' perception over a social perspective after they had experienced the English course. The results showed that the course was the first contact with the English Language for most of the students and that the opportunity has stimulated them to carry on their studies, regarding the benefits that a second language can bring to their social life.
\end{abstract}

Resumo. $O$ estudo relatado neste artigo apresenta a experiência de oferta de um minicurso de Inglês a distância para alunos do curso de Pedagogia na modalidade EAD da UFRPE e residentes no interior do estado de Pernambuco. O objetivo da pesquisa foi analisar a percepção dos alunos sob uma perspectiva social após a experiência de realizar o minicurso. Os resultados obtidos apontam que o minicurso representou uma primeira oportunidade de contato com a língua inglesa para a maioria dos alunos e estimulou-os a continuar em busca da aquisição da língua, o que pode oferecer-lhes mais e diferentes condições de posicionamento na sociedade.

\section{Introdução}

As evidências da grande necessidade da Língua Inglesa no mercado de trabalho e no universo acadêmico-científico possibilitam um novo olhar no trato com o Inglês no século XXI. A língua Inglesa é, indubitavelmente, imprescindível nos dias atuais. Décadas atrás, várias discussões acerca da importância da aquisição e domínio do idioma já existiam e no atual momento, a importância fica ainda mais evidente diante das crescentes exigências do mundo corporativo e do mercado de trabalho. Além disso, o inglês é requerido para a efetiva participação do estudante que deseje atuar no universo acadêmico-científico e como pesquisador.

Desse modo, a relevância da língua ganha uma amplitude cada vez maior, ultrapassa os limites do 'falar uma segunda língua' e esbarra no âmbito do posicionamento do indivíduo em relações diversas. 
Apesar dessa realidade de grande importância que o Inglês possui na formação profissional e acadêmica dos estudantes, em diversos contextos educacionais de Ensino Superior, ainda não existe a oferta de disciplinas de Língua Inglesa nos currículos. Não somente, grande parte dos alunos universitários não possui tempo disponível para participar de cursos presenciais.

Nesse sentido, a Educação a Distância se apresenta como uma alternativa interessante. Os recursos multimídia e interativos no ensino de língua inglesa são fundamentais e a EAD oferece diversos recursos tecnológicos que podem ser utilizados no ciberespaço para facilitar a produção do conhecimento. Ademais, a utilização de recursos multimídia e interativos, inerente à EAD, pode, no aprendizado da língua inglesa, motivar os alunos uma vez que proporcionam mais individualidade, fazendo com que cada um respeite o seu ritmo, promovendo assim, aprendizagens mais personalizadas [Lévy, 1999].

Assim sendo, o estudo apresentado neste artigo objetivou investigar o impacto social da oferta de um minicurso de Inglês a distância, oferecido para alunos do curso de Pedagogia na modalidade EAD, residentes em um município localizado no interior do estado de Pernambuco. A escolha pela investigação da variável de impacto social deu-se a partir da dificuldade de, na primeira experiência com o minicurso, avaliar a construção da aprendizagem. E, sobretudo, pelas experiências exitosas, no tocante à contribuição da EAD para a sociedade, a partir da aplicação e utilização dessa modalidade de ensino em outras áreas.

Santos e Rafalski (2014), por exemplo, apresentam em seu trabalho o impacto da inclusão digital na esfera social, relatando a melhoria da autoestima e desempenho dos alunos participantes de cursos técnicos do Centro de Estadual de Educação Técnica Vasco Coutinho, localizado no município de Vila Velha, estado do Espírito Santo. Malaquias et al (2012) apontam a contribuição de um ambiente virtual de aprendizagem (AVA) para a efetiva inclusão de alunos com deficiência mental na escola. O AVA foi desenvolvido com vistas a proporcionar mais condições para os alunos atuarem mais autonomamente na sociedade.

Entretanto, não foi possível encontrar em periódicos e anais de eventos de abrangência e relevância nacionais relatos de pesquisas cujo enfoque apresente investigações na área de ensino de Inglês. Nesse sentido, a presente pesquisa justifica-se pelo interesse em apresentar, à comunidade científica, resultados que possam contribuir para novos aprofundamentos de estudos na área em questão. Esses estudos podem possibilitar a oferta da língua para indivíduos que ainda não têm acesso ao idioma assim como possibilitar a inserção de disciplinas de Língua inglesa nos currículos brasileiros.

Para a realização da pesquisa, foi criado um minicurso de Inglês a distância para estudantes da Universidade Federal Rural de Pernambuco matriculados no curso de Pedagogia na modalidade EAD.

\section{Processo de ensino-aprendizagem de Inglês para adultos, mediado por tecnologias}

De acordo com Harmer (2007), os alunos adultos possuem uma vasta experiência de vida que pode contribuir com o processo de ensino-aprendizagem. Eles têm as expectativas acerca do 
processo e geralmente sabem seu papel dentro desse contexto. Além disso, para o autor, os adultos são capazes de sustentar o grau de motivação por mais tempo.

Ainda segundo a linha de pensamento do autor supracitado, há algumas considerações que devem ser analisadas acerca do ensino de Inglês para adultos que incluem a capacidade crítica dos alunos adultos para as metodologias de ensino adotadas. Não somente, os adultos podem ter tido experiências negativas no aprendizado da língua o que contribui para uma ansiedade e, sobretudo, falta de confiança para aprender o idioma. Williams e Burden (1997) pontuam que alunos mais velhos preocupam-se com sua capacidade intelectual e acreditam que, com o tempo, a habilidade cognitiva para aprender diminui. A partir da utilização de recursos disponíveis no ciberespaço e na Internet, a construção do conhecimento da língua pode ser dar de forma mais efetiva. Esses recursos podem funcionar como ferramentas didáticas de apoio ao professor para que encoraje o aluno, diminuindo as dificuldades e barreiras existentes.

No século XXI, as formas como as tecnologias estão sendo utilizadas em salas de aula de ensino de Inglês em todo o mundo têm sido parte fundamental para a prática da língua [Motteram, 2013]. Motteram (2013) aponta a diversidade de contribuições de tecnologias usadas no ensino de Inglês em uma série de estudos de casos conduzidos em diversos países. De acordo com Masetto (2012), as tecnologias começaram a ser valorizadas pelo fato de se criar possibilidades como: acesso mais fácil à pesquisa e a várias informações e oportunidades de estimular a autoaprendizagem. A tecnologia pode facilitar e oportunizar o estudante a aprender mesmo a distância, em qualquer lugar, a qualquer hora.

No ensino de Inglês, Harmer (2007) aponta os aportes digitais e tecnológicos como elementos eficazes na produção do conhecimento. No ensino de Inglês para adultos, a relação entre aprendizado e autonomia estreita-se e Paiva (2001) defende que o material da Internet pode oferecer maior autonomia ao aluno.

Além disso, os recursos multimídia e interativos podem, no aprendizado da língua inglesa, motivar os alunos uma vez que proporcionam mais individualidade, fazendo com que cada um respeite o seu ritmo. Outro aspecto, a respeito dos recursos multimídia e interativos, é a possibilidade de realizar trabalho com gêneros textuais, muito utilizados no ensino de qualquer língua nos últimos anos, devido à relação estreita entre os gêneros e o mundo. Marcuschi (2004) aponta o surgimento de gêneros virtuais com o advento da Internet.

No contexto de Educação a Distância, o ambiente Moodle, segundo o seu criador Dougiamas (1998 apud Franco, 2009), oferece suporte necessário para estimular diversas situações de comunicação entre os participantes, necessárias no aprendizado de um idioma. A EAD, portanto, mediada por um número grande de recursos tecnológicos, aparece como um cenário propício para o desenvolvimento do conhecimento de Língua Inglesa.

\section{Metodologia}

Para análise do objeto de investigação do estudo foram observados os fatos na experiência da oferta de um minicurso de Inglês na modalidade a distância para alunos do curso de Pedagogia da Universidade Federal Rural de Pernambuco (UFRPE). Foi realizada uma pesquisa com abordagem quantitativa e qualitativa cujo objetivo foi analisar o impacto no âmbito social do minicurso a partir da percepção dos alunos cursistas. Para tanto, foram respondidos pelos participantes questionários com perguntas objetivas e subjetivas. Os 
questionários foram disponibilizados no Ambiente Virtual de Aprendizagem (AVA) ao término do curso.

Os dados extraídos das questões objetivas foram organizados a partir de uma análise estatística descritiva sendo dispostos em gráficos para melhor compreensão dos resultados. Os dados da pesquisa sobre a opinião e a avaliação dos participantes acerca da experiência ao realizar o minicurso foram coletados também através de algumas falas dos estudantes no dia do encontro presencial que ocorreu. As questões subjetivas e as falas foram analisadas com enfoque interpretativista para registrar as vozes dos participantes do curso.

Os questionários foram divididos considerando três parâmetros: Avaliação geral do Minicurso, Avaliação da Metodologia adotada e Autoavaliação da Aprendizagem e Participação. Neste trabalho, apresentaremos os dados e posterior análise obtidos no questionário de avaliação geral do minicurso e da autoavaliação da aprendizagem com vistas a obter dados sob uma ótica social, objetivo central da pesquisa.

Foram respondidos 24 questionários. As perguntas eram em sua maioria com respostas de 'sim' ou 'não'. No entanto, os respondentes eram convidados a justificar sua resposta ou fazer um comentário que desejasse.

\subsection{Minicurso de Inglês com fins de leitura, oferecido na modalidade a distância}

O minicurso na modalidade a distância foi desenvolvido com fins de auxiliar os estudantes no processo de leitura de textos em Língua Inglesa em que foram utilizados diversos gêneros textuais para praticar a habilidade. No entanto, a análise investigativa proposta para o estudo relatado neste artigo, concentra-se na observação da percepção dos estudantes, sob uma perspectiva de efeito social, a partir da vivência do minicurso.

O curso foi oferecido para estudantes do curso de Pedagogia, na modalidade a distância, da Universidade Federal Rural de Pernambuco (UAB/EAD/UFRPE). O minicurso ocorreu em um período de 2 meses, entre Maio de 2016 e Julho do mesmo ano. Foram inscritos 34 estudantes dos quais 25 participaram ativamente do curso. $\mathrm{O}$ curso foi dividido em 6 semanas, com carga horária de 30 horas, sendo ministrado por duas professoras/ tutoras. Todos os estudantes participantes do minicurso eram do sexo feminino das quais, apenas $4 \%$ tinham menos de 24 anos, $58 \%$ tinham entre 25 e 34 anos, $13 \%$ tinham entre 35 e 44 anos e 25\% tinham mais de 45 anos. Todas as participantes residem no município de Carpina, no interior do estado de Pernambuco.

Ao final das seis semanas, ocorreu um Encontro Presencial no município de Carpina. Nesse momento, os alunos tiveram uma aula e uma conversa informal com as duas professoras para feedback do curso. $\mathrm{O}$ encontro presencial teve carga horária de 4 horas.

Nos dois primeiros dias de curso, percebeu-se que as estudantes encontraram dificuldades no preenchimento de formulários digitais. E, então, o questionário inicial para conhecimento de perfil que havia sido disponibilizado foi modificado para um questionário no Word. Esse questionário objetivou pesquisar as características do grupo para o qual o minicurso seria oferecido com vistas a dialogar com as necessidades e dificuldades dos cursistas em relação ao letramento digital e principalmente em relação às dificuldades relacionadas à Língua Inglesa.

A partir desse questionário, foram observadas dificuldades linguísticas com relação a conhecimentos básicos do idioma, sendo necessário realizar algumas mudanças no planejamento do curso. Além disso, para minimizar essas dificuldades, 
foram sugeridos materiais de estudo com explicações gramaticais em Português, paralelamente ao conteúdo proposto para o minicurso, para auxiliar os alunos na realização das atividades e compreensão dos conteúdos.

Ainda nesse questionário, alguns estudantes revelaram sua satisfação em poder ter a oportunidade de fazer um minicurso de Inglês. Outros, entretanto, colocaram que só haviam se inscrito no minicurso por ser a única opção oferecida pela Universidade como atividade complementar para conclusão de carga horária exigida. No entanto, ao término do minicurso, esses alunos afirmaram ter sido proveitoso e que escolheriam o minicurso em outra ocasião, como será pontuado na seção de resultados.

Utilizamos a ferramenta fórum para criar um fórum de notícias. No entanto, foi disponibilizado apenas na primeira semana de atividades, pois as alunas se reportavam às professoras executoras através de mensagem pessoal. Não houve efetiva participação das alunas no sentido de alimentar as ferramentas colaborativas sugeridas no início do minicurso. Acreditamos que por falta de tempo, devido à quantidade de disciplinas que elas precisavam concluir, ou por falta de costume em utilizar essas ferramentas.

O minicurso foi ministrado por duas professoras- e autoras desse artigo- e teve como proposta de conteúdo o trabalho com gêneros textuais. A partir de gêneros textuais foram introduzidos os conteúdos. A saber: cognatos e falsos cognatos da língua inglesa, sufixos, conectores, partes do discurso e estratégias de leitura de textos em Inglês. O material utilizado ao longo do curso foi uma apostila (Leitura Instrumental de Textos em Língua Inglesa) escrita pelas professoras.

As dificuldades encontradas ao longo do curso como: pouco conhecimento prévio dos alunos, dificuldades linguísticas e dificuldade com o tempo para estudar nos levaram a modificar o planejamento e ir construindo o minicurso a partir das necessidades pessoais e acadêmicas dos estudantes. Além disso, contribuíram para nossa autoavaliação e para possíveis ajustes e aprimoramentos no curso.

\section{Resultados}

Inicialmente, as justificativas e comentários dos cursistas nos questionários mostraram grande satisfação após a oportunidade do minicurso como pode ser visto nos excertos a seguir com exemplos de falas de duas alunas: "o que mais gostei foi aprender a fazer tradução de textos com a ajuda do Google tradutor, pois nem isso sabia fazer"; "pra mim que não sabia de nada, já adquiri algum conhecimento, isso foi valioso".

Dessas participantes, apenas $18 \%$ já haviam tido oportunidade de estudar Inglês anteriormente. Ou seja, esse minicurso de Inglês a distância foi a primeira oportunidade de essas alunas entrarem em contato com o idioma em um contexto formal de aprendizagem. Possivelmente, elas não poderiam participar de um curso presencial mas sendo a distância isso foi possível. Em contrapartida, 87\% afirmaram ter vontade de estudar o idioma. A partir do dado observado, podemos inferir a importância social da oferta do minicurso para as alunas que nunca haviam tido oportunidade de adquirir conhecimento de língua inglesa, a qual as possibilitaria mais ou diferentes condições de posicionamento na sociedade.

As participantes responderam se se sentiam mais encorajadas a ler textos em Inglês após o Minicurso. O Gráfico 1 mostra que dos 100\%, 83\% afirmaram se sentir mais 
VI Congresso Brasileiro de Informática na Educação (CBIE 2017)

Anais do XXIII Workshop de Informática na Escola (WIE 2017)

encorajados a ler textos em Inglês após o minicurso enquanto $17 \%$ afirmaram ainda não estarem seguras para fazê-lo.

Gráfico 1. Segurança dos alunos para ler textos em Inglês após o curso.

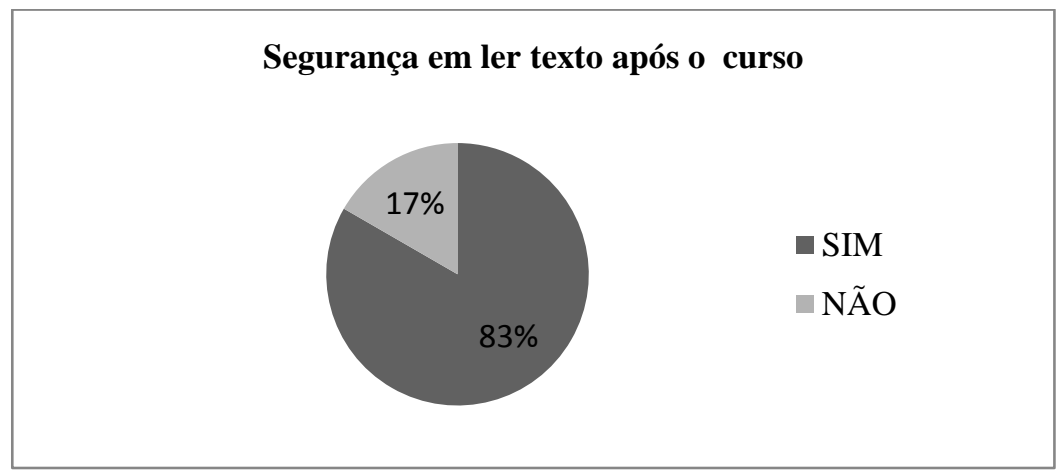

Em seguida, os participantes apontaram sua opinião acerca da importância do Inglês para a formação de professores e para a continuação de seus estudos acadêmicos. Dos participantes, 92\% afirmaram que o aprendizado do Inglês é importante para sua formação continuada e para a continuação de seus estudos acadêmicos. Apenas 8\% responderam não considerar importante, como pode ser observado no Gráfico 2.

Gráfico 2. Opinião dos alunos acerca da importância do conhecimento de Inglês.

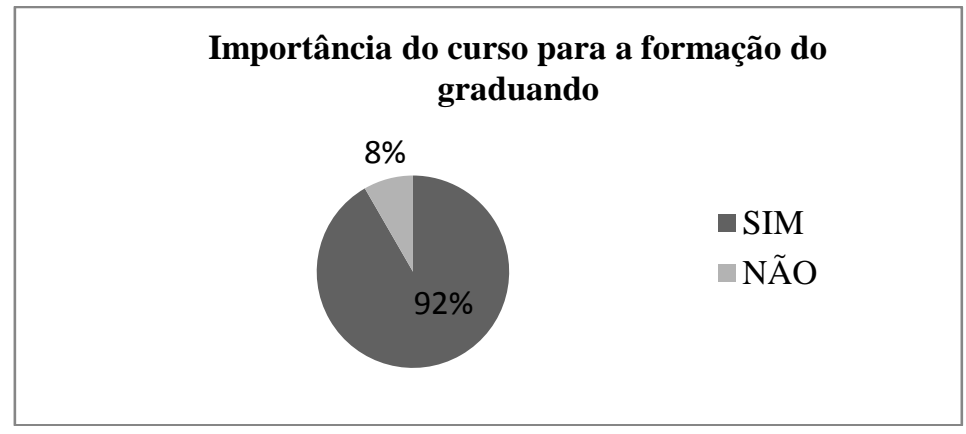

Os participantes foram questionados também se indicariam o minicurso para um amigo e $100 \%$ dos alunos afirmaram que indicariam o curso.

Em seguida, os participantes foram perguntados se continuariam o curso se houvesse um segundo módulo. $87 \%$ dos respondentes indicaram que continuariam o curso em um segundo módulo e $13 \%$ afirmaram que não continuariam. Os dados podem ser observados no Gráfico 3.

Gráfico 3. Opinião dos participantes acerca da continuação do minicurso caso houvesse outro módulo.

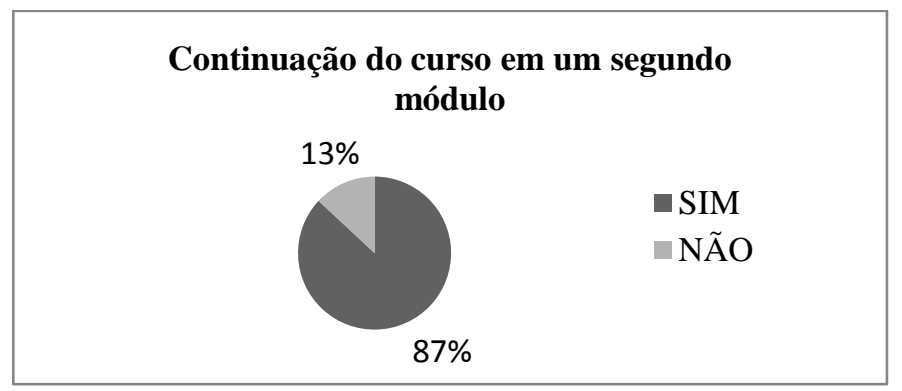


Os participantes deram também sua opinião acerca dos conteúdos trabalhados no minicurso. À esta questão, $100 \%$ dos respondentes afirmaram que os conteúdos propostos para o minicurso despertaram interesse pelo curso.

Posteriormente, os respondentes opinaram a respeito do tempo de duração do minicurso. O Gráfico 4 mostra que $78 \%$ dos respondentes consideram a duração do curso curta e $22 \%$ afirmaram considerar a duração suficiente. Nenhum dos respondentes considerou o minicurso longo.

\section{Gráfico 4. Opinião dos participantes acerca da duração do minicurso}

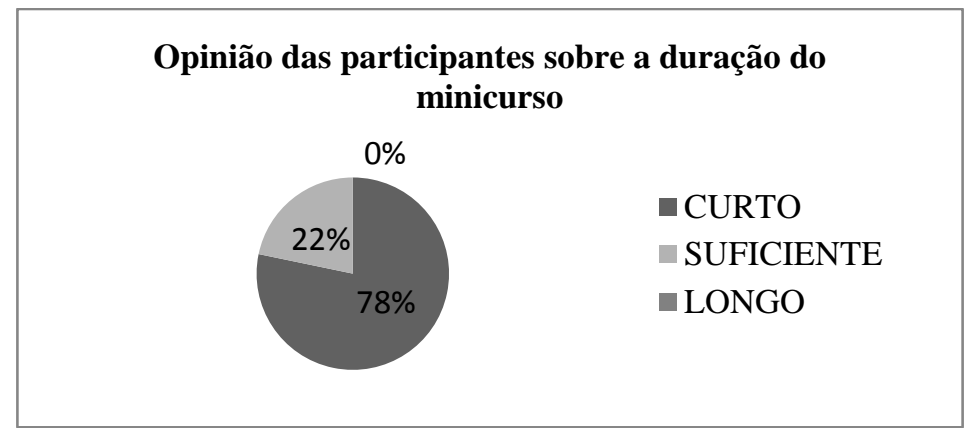

Finalmente, os participantes opinaram a respeito da interatividade do minicurso. O Gráfico 5 indica que $86 \%$ dos estudantes acharam o curso interativo. $14 \%$ deles consideraram que o curso não foi interativo.

Além disso, os cursistas em sua totalidade consideraram que o curso foi interessante e que as professoras demonstraram interesse pela aprendizagem dos alunos, utilizando linguagem dialógica e acessível e afirmaram que os comentários e feedbacks das tarefas contribuíram para a construção do aprendizado.

No questionário sobre a autoavaliação da aprendizagem, os cursistas responderam a duas perguntas. Primeiramente foram convidados a avaliar sua participação considerando se foi: excelente, boa, regular ou fraca. O Gráfico 6 mostra que $65 \%$ dos cursistas consideraram sua participação boa. Apenas $5 \%$ avaliaram como excelente. Outros $20 \%$ consideraram regular e $10 \%$ acharam que sua participação foi fraca.

Gráfico 5. Opinião das participantes sobre a interatividade do minicurso.

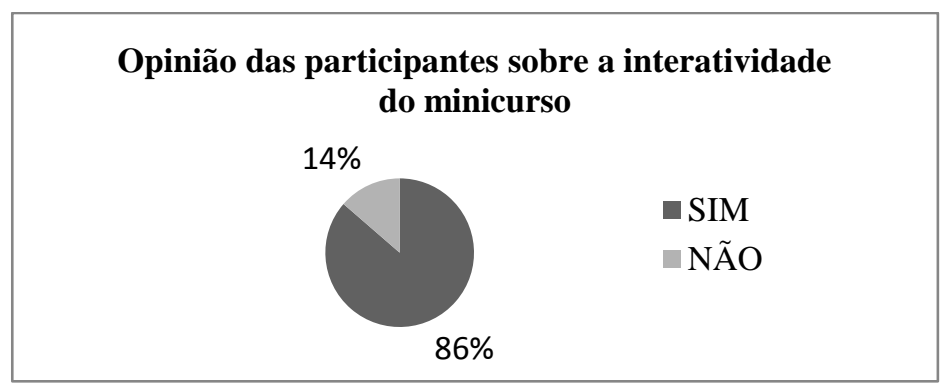


VI Congresso Brasileiro de Informática na Educação (CBIE 2017)

Anais do XXIII Workshop de Informática na Escola (WIE 2017)

\section{Gráfico 6. Opinião dos cursistas sobre a sua participação}

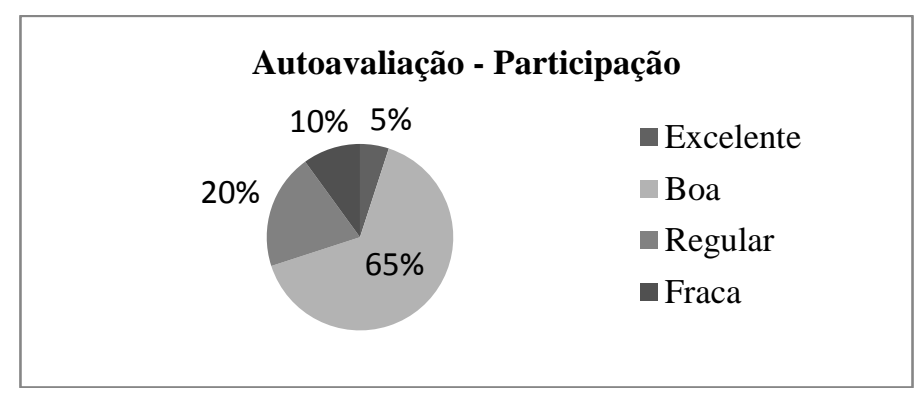

$\mathrm{Na}$ segunda pergunta os participantes fizeram uma autoavaliação do desempenho considerando novamente entre: excelente, bom, regular ou fraco. A maioria dos cursistas, 55\%, considerou seu desempenho bom enquanto apenas 5\% acharam que foi excelente. $40 \%$ avaliaram o desempenho como regular e nenhum dos participantes considerou fraco, como observado no Gráfico 7.

\section{Gráfico 7. Avaliação dos cursistas sobre o seu desempenho}

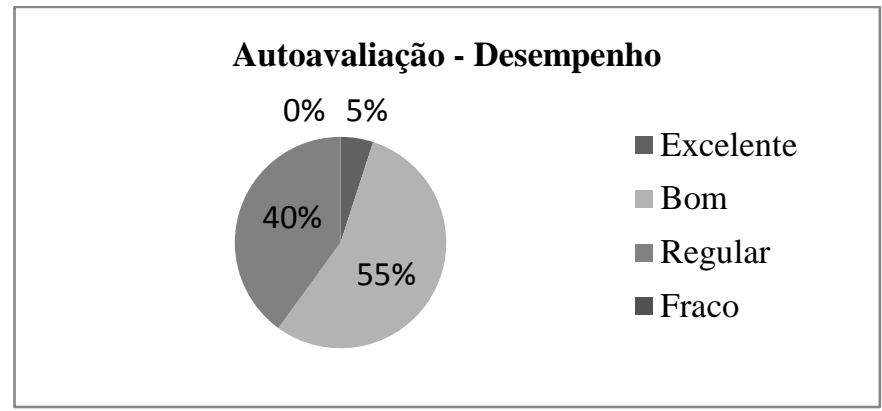

No encontro presencial realizado para concluir o minicurso, as professoras realizaram uma conversa com as alunas fazendo algumas perguntas para obter feedback do curso. Inicialmente, as alunas foram questionadas se puderam reconhecer, nas atividades do encontro presencial, os conteúdos trabalhados no ambiente virtual. Algumas falas das alunas são vistas nos excertos a seguir: "Hunrum" "Com certeza" "Tudo" "Reconhecemos".

As falas mostram que as alunas lembravam os conteúdos mesmo tendo apresentado dificuldade na realização das tarefas ao longo do curso. Além disso, apesar da dificuldade com o idioma, o reconhecimento do conteúdo na aula presencial mostra que possivelmente houve assimilação do mesmo.

Em seguida, as alunas foram questionadas se conseguiriam realizar a atividade feita no encontro presencial, se não tivessem tido o curso no ambiente virtual. Algumas respostas das alunas são vistas nos excertos a seguir: "Conseguia não"; "Nem sabia o que eram cognatos"; "Não".

Mais uma vez, as falas apontam que apesar das dificuldades encontradas ao longo do curso, as alunas assimilaram um pouco do conteúdo da língua através de um minicurso a distância. Outra evidência da assimilação do conteúdo diz respeito à realização das tarefas na aula presencial as quais foram realizadas satisfatoriamente pelas alunas. 
O quadro 1 mostra algumas colocações gerais das alunas acerca do minicurso e suas contribuições. Além disso, apresenta algumas respostas das alunas quando questionadas se tentavam ler textos em Inglês antes do minicurso.

Quadro 1. Falas das alunas no encontro presencial

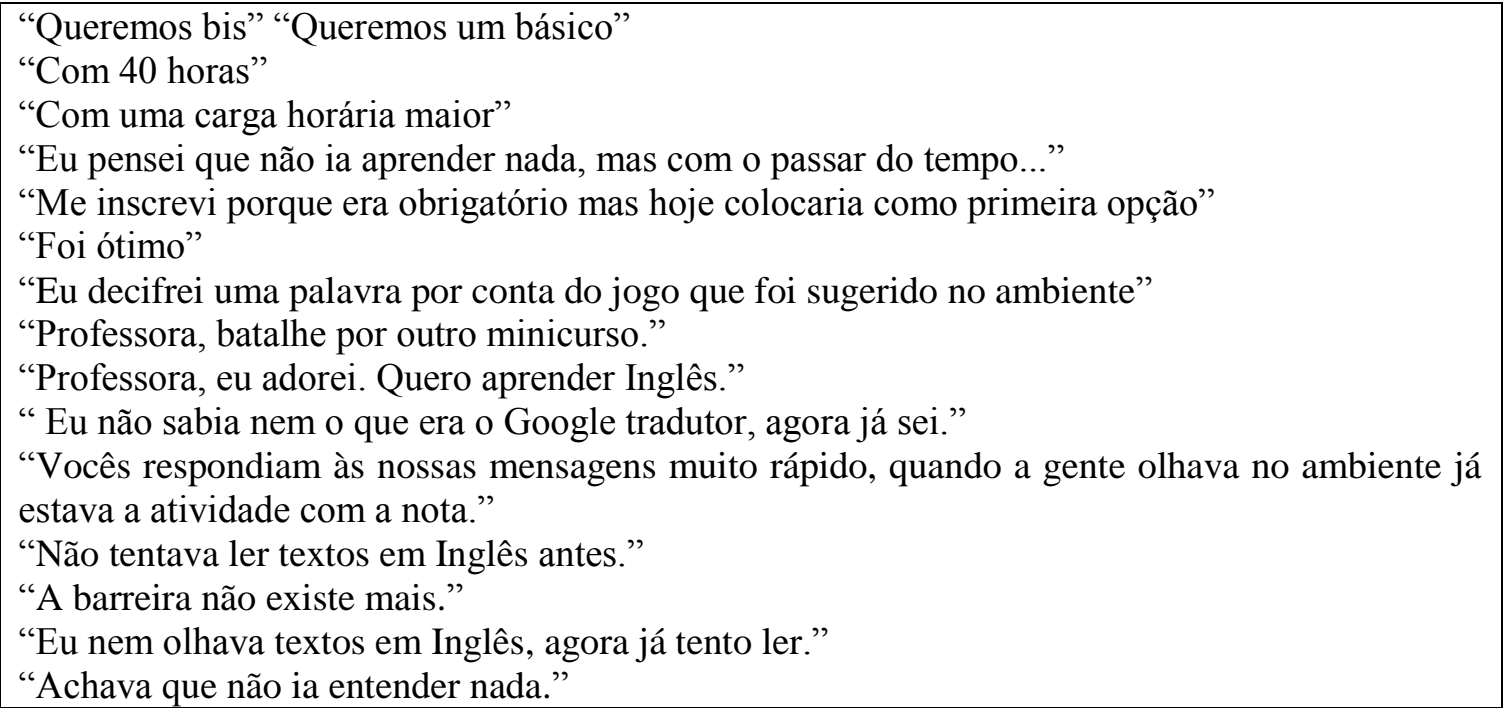

As falas indicam que as alunas ficaram satisfeitas com o curso e motivadas para novos possíveis cursos nesse contexto e para aprender a língua. A partir das falas apontadas no quadro 1 pode-se inferir a contribuição do curso, não somente para o aprendizado de Inglês, mas também a sua contribuição social quando as alunas apresentam ter aumentado o interesse em buscar aprender coisas novas e enfrentar novos desafios antes considerados muito distantes de suas realidades.

\section{Considerações finais}

A aprendizagem de Inglês é fundamental, nos dias atuais, para uma efetiva participação do indivíduo na vida acadêmica e profissional. A oferta de ensino-aprendizagem da língua, entretanto, ainda não é uma prática comum em todos os contextos de Ensino Superior no país. A Educação a Distância como modalidade de ensino, que utiliza os mais variados recursos tecnológicos na promoção da aprendizagem, é uma alternativa para a inserção de Inglês dentro dos currículos dos cursos de Graduação.

O presente trabalho apresentou os resultados de uma pesquisa cujo enfoque investigativo foi analisar a percepção dos alunos aos quais foi oferecido um minicurso de Inglês a distância. A análise dos dados obtidos foi feita a partir de uma perspectiva de impacto social da oferta do curso.

Os resultados apontaram que a oportunidade do minicurso foi a primeira oportunidade para a maioria dos alunos, revelando a importância da oferta do curso na vida social desses estudantes. Não somente, a partir dos resultados obtidos, pode-se observar que o minicurso de Inglês motivou os alunos a continuar em busca do conhecimento e aquisição da Língua Inglesa o que pode oferecer-lhes mais e diferentes condições de posicionamento na sociedade.

Os resultados do minicurso foram positivos de acordo com os dados fornecidos pelas alunas. Entretanto, algumas considerações foram feitas pelas professoras 
formadoras. Desde o começo, foram observadas dificuldades linguísticas com relação a conhecimentos básicos da Língua Inglesa, sendo necessário realizar algumas mudanças em relação ao planejamento do curso. As dificuldades apresentadas revelaram, principalmente, o fator social de carência de ensino de Inglês para alunos brasileiros, sobretudo residentes em municípios localizados nos interiores dos estados do país.

Ademais, as dificuldades observadas conduziram a uma reflexão acerca da necessidade de se continuar investigando melhores técnicas para o ensino de Inglês a distância dentro do contexto dos discentes, atores da Educação a Distância da UFRPE. As metodologias de ensino na EAD devem ser constantemente revisitadas e reavaliadas para que possa haver ajustes antes, durante e depois do planejamento, ajustando-o às necessidades do público-alvo e agregando diferentes ferramentas tecnológicas. Trabalhos futuros decorrentes desse estudo visam, então, atuar nesse campo de investigação.

Na medida em que novas pesquisas na área de ensino de Inglês na modalidade a distância são realizadas, aumenta-se a probabilidade de aprimoramento da criação de disciplinas de ensino da língua. Assim sendo, esses novos objetos de investigação e novos mergulhos de pesquisa podem contribuir para que o ensino da língua inglesa se expanda, oportunizando estudantes de diversas regiões, sobretudo em locais aonde a EAD chegou e ofereceu novas perspectivas acadêmicas, a ter acesso ao aprendizado do idioma.

\section{Referências}

Franco, C. P. (2009) "O uso de um ambiente virtual de aprendizagem no ensino de inglês: além dos limites da sala de aula presencial”. Dissertação de Mestrado, Programa Interdisciplinar de Pós-Graduação em Linguística Aplicada, Faculdade de Letras, Universidade Federal do Rio de Janeiro. Rio de Janeiro.

Harmer, J. (2007) "The practice of English Language Teaching”. Pearson. Longman. Cambridge, Uk.

Levy, P. (1999) “Cibercultura”.São Paulo: Ed. 34.

Malaquias, F.; Junior, E.; Cardoso, A.; Santos, C.; Pacheco, M. (2012) "VirtualMat: um ambiente virtual de apoio ao ensino de Matemática para alunos com deficiência mental”. Revista Brasileira de Informática na Educação, v.20, n.2.

Marcuschi, L. A. (2004)"Gêneros textuais emergentes no contexto da tecnologia digital”. In: MARCUSCHI, L. A.; XAVIER, A. Hipertexto e gêneros digitais: novas formas de construção de sentido. Rio de Janeiro: Lucerna.

Masetto, M. (2012) "Mediação pedagógica e o uso da tecnologia". In: Novas tecnologias e Mediação Pedagógica. 19 ed. Campinas, SP: Papirus.

Motteram, G. (org) (2013) "Innovations in learning for English language teaching". British Council.

Paiva, V. L M. O. (2001)“A WWW e o Ensino de Inglês. Revista Brasileira de Lingüística Aplicada”. v. 1, n1, p. 93-116.

Santos, W.; Rafalski, J. (2014) "Oficina de inclusão digital para a construção social: estudo de caso no CEET Vasco Coutinho- Espírito Santo”. Revista Brasileira de Informática na Educação, v.22, n.3.

Williams, M.; Burden, R. (1997)“Psychology for Language Teaching”.Oxford University Press. 